\title{
Development of new bilberry (Vaccinium myrtillus L.) based snacks: Nutritional, chemical and bioactive features
}

\author{
Tânia C.S.P. Pires ${ }^{\mathrm{a}, \mathrm{b}}$, Maria Inês Dias ${ }^{\mathrm{a}}$, Ricardo C. Calhelha ${ }^{\mathrm{a}}$, Maria José Alves ${ }^{\mathrm{a}}$, \\ Celestino Santos-Buelga ${ }^{\mathrm{b}}$, Isabel C.F.R. Ferreira ${ }^{\mathrm{a}, *}$, Lillian Barros ${ }^{\mathrm{a}, *}$ \\ ${ }^{a}$ Centro de Investigação de Montanha (CIMO), Instituto Politécnico de Bragança, Campus de Santa Apolónia, 5300-253 Bragança, Portugal \\ ${ }^{\mathrm{b}}$ Grupo de Investigación en Polifenoles (GIP-USAL), Facultad de Farmacia, Universidad de Salamanca, Campus Miguel de Unamuno s/n, 37007 Salamanca, Spain
}

\section{A R T I C L E I N F O}

\section{Keywords:}

Edible petals

Fruits

Non-anthocyanin and anthocyanin phenolic

Antioxidant capacity

Antibacterial activity

Novel food products

\begin{abstract}
A B S T R A C T
The sustainable exploitation of fruit and cereal processing is being conducted to produce novel food products with promising nutritional properties and high content in added value compounds. Herein, three bilberry fruitbased snacks supplemented with edible petals and fruits were characterized for their nutritional properties and chemical composition. The phenolic profile, antioxidant, antibacterial and hepatotoxic properties were analyzed. Protein (3-4 g/100 g dw) and carbohydrates (94.3-94.8 g/100 g dw) represented the major macronutrients. The combination of bilberry fruits with edible petals, calendula and rose, improved the nutritional and phytochemical input in organic acids and tocopherols content, respectively. Also, the supplementation with apple and goji fruits provided higher content in phenolic acids and anthocyanins (up to a 9-fold higher concentration, $199.7 \mu \mathrm{g} / \mathrm{g}$ of extract), also resulting in a higher antioxidant and antibacterial activities. The results obtained can contribute for the development of novel sustainable and healthier snacks for the food industry.
\end{abstract}

\section{Introduction}

The current food system faces many challenges in terms of sustainability, an issue that must be approached cautiously and efficiently so that all environmental, social and economic consequences of production/processing and further consumption could be foreseen (Verain, Dagevos, \& Antonides, 2015). At the same time, there is an increasing trend for food products that are safe, natural, and with various claims, such as biodegradable, fair trade, cruelty-free, healthy and sustainable (Forbes, Kahiya, \& Balderstone, 2016). Snack food products consumption has increased exponentially worldwide over recent decades, already representing a significant part of the daily intake of nutrients as they are consumed throughout the day between the traditional three meals to promote satiety and suppress overconsumption at the subsequent meals (Forbes et al., 2016; Njike et al., 2016). The importance of these type of products in everyday life-style is already so significant that in Europe the sustainable exploitation of fruit and cereal processing by-products is being conducted to the development of new food products, including snacks (Fava et al., 2013) Among the many fruits that could be considered, Vaccinium myrtillus L. (Ericaceae family), also known as European blueberry, huckleberry, whortleberry or bilberry, appears as one of the most interesting matrices. The popularity of bilberry fruit can be ascribed to their balanced sweet sour taste and nutritional value (Mikulic-Petkovsek, Schmitzer, Slatnar, Stampar, \& Veberic, 2015), but are perishable seasonal products and the shelf-life of fresh berries is normally short, for this, drying is a commonly used to preserve and extended shelf life, increasing the commercial value and reduce waste, so it is reasonable to process berries into more stable products namely extruded snacks (Höglund et al., 2018). The berries are a rich source of various phenolic compounds which have been linked to their antioxidant potential. It contains particularly high levels of anthocyanins, associated to antimicrobial, anti-inflammatory and anti-mutagenic properties (Zorenc, Veberic, Stampar, Koron, \& MikulicPetkovsek, 2016), which have been reported to contribute for the prevention of a number of diseases such as type 2 diabetes and cardiovascular diseases (Donno et al., 2019). Furthermore, the combination of the properties of bilberry fruits with other fruits, or even edible flowers can result in the production of new food products. For instance, 'Bravo de Esmolfe', a Portuguese apple variety highly appreciated by consumers, has shown antioxidant and antibacterial activity against Gram-positive and Gram-negative bacteria (Pires et al., 2018a) or goji fruits that have been described as having bioactive compounds with antioxidant and antimicrobial properties (Liu et al., 2012; Pires et al., 2018b). Donno et al. (2019) developed a novel snack based on freeze-

\footnotetext{
* Corresponding authors.

E-mail addresses: iferreira@ipb.pt (I.C.F.R. Ferreira), lillian@ipb.pt (L. Barros).
} 
dried apple, kiwifruit, and goji fruits, providing a complete and interesting chemical and nutritional profile. Also, Sepúlveda et al. (2011) developed an apple snack to reduce obesity in school children between the ages of 8 and 12 years old, with high acceptability among the consumers due to the crunchy texture and bittersweet flavor, being an alternative for school snacks. There is also an increasing interest in edible flowers (Fernandes, Casal, Pereira, Saraiva, \& Ramalhosa, 2017), not only because of their appealing flavor and appearance, but also for their nutritional, antioxidant and antimicrobial activities (Pires et al., 2018c), which explains the rising trend in their sales worldwide.

Edible flowers are consumed fresh (salads), dried or canned in sugar, as well as incorporated in cocktails in ice cubes, preserved in distillate products or as pickles in vinegar and salt or as an ingredient in different meals like beverages, being its consumption associated to different health benefits, namely antibacterial, antitumor, antithrombotic, diuretic, and hypotensive effects (Pires, Barros, SantosBuelga, \& Ferreira, 2019). Also edible flowers are consumed as infusions and incorporated into cakes or used in the development of children's snacks as a described by Łuczaj et al., 2012. As far as the authors knowledge there are no studies in literature on bilberry-based food products combined with different types of fruits and edible flowers. The present study aims at evaluating the nutritional, chemical and phenolic composition, as also the bioactive potential of the combination of Vaccinium myrtillus with rose and calendula petals, dehydrated apple and goji berries, so as to develop novel food products, namely snacks, that can provide consumers healthier choices and meet their food concerns. The overall objective is to develop a more complete product, able to satisfy nutritional needs, as well as providing different health benefits that result from the combination of the different matrices already described.

\section{Materials and methods}

\subsection{Samples}

Four different samples (50 g each) commercialized by RBR Foods Company (Castro Daire, Portugal) as snacks, were supplied in the dry form. The samples consisted in mixtures of Vaccinium myrtillus L. fruits with petals from Rosa damascena 'Alexandria' and R. gallica 'Francesa' draft in $R$. canina, petals from Calendula officinalis L., mesocarp of Malus domestica Borkh. cv 'Bravo de Esmolfe', and Lycium barbarum L. fruits. Pictures of the different mixtures and their composition are shown in Table 1. Throughout the manuscript these products are designed by their common names, i.e., bilberry fruits, rose, calendula, apple, and goji fruits, respectively. The composition of the samples was the following: i) P0 sample constituted by bilberry fruits (50 g, 100\%); ii) mixture $P 1$ contained $49 \mathrm{~g}$ of bilberry fruits (98\%) and $1 \mathrm{~g}$ of rose petals (2\%); iii) mixture $P 2$ contained $49.97 \mathrm{~g}$ of bilberry fruits (99.98\%) and $0.03 \mathrm{~g}(0.02 \%)$ of calendula petals; and mixture $P 3$ contained $30 \mathrm{~g}$ of bilberry fruits (60\%), $18 \mathrm{~g}$ of dehydrated apple "Bravo de Esmolfe" $(36 \%)$ and $2 \mathrm{~g}$ of goji fruits (4\%). After reception, the mixtures were reduced to a fine powder ( 20 mesh) and mixed to obtain homogenate samples.

\subsection{Proximate composition and energetic value}

The content in proteins, fat, carbohydrates and ash was analyzed in the dry powder mixtures following the procedures previously described by the Association of Official Analytical Chemists (AOAC, 2016). AOAC procedure 991.02 was used to determine the crude protein content $(\mathrm{N} \times 6.25$, macro-Kjeldahl method); AOAC 989.05 was used for crude fat (Soxhlet apparatus with petroleum ether as extraction solvent) determination; finally, for ash content determination (incineration at $550 \pm 15^{\circ} \mathrm{C}$ ) AOAC 935.42 was used. The total carbohydrates (fiber included) content were calculated by difference of the previously determined factors, following the equation: Total carbohydrates $(\mathrm{g} /$
Table 1

Composition of the mixtures

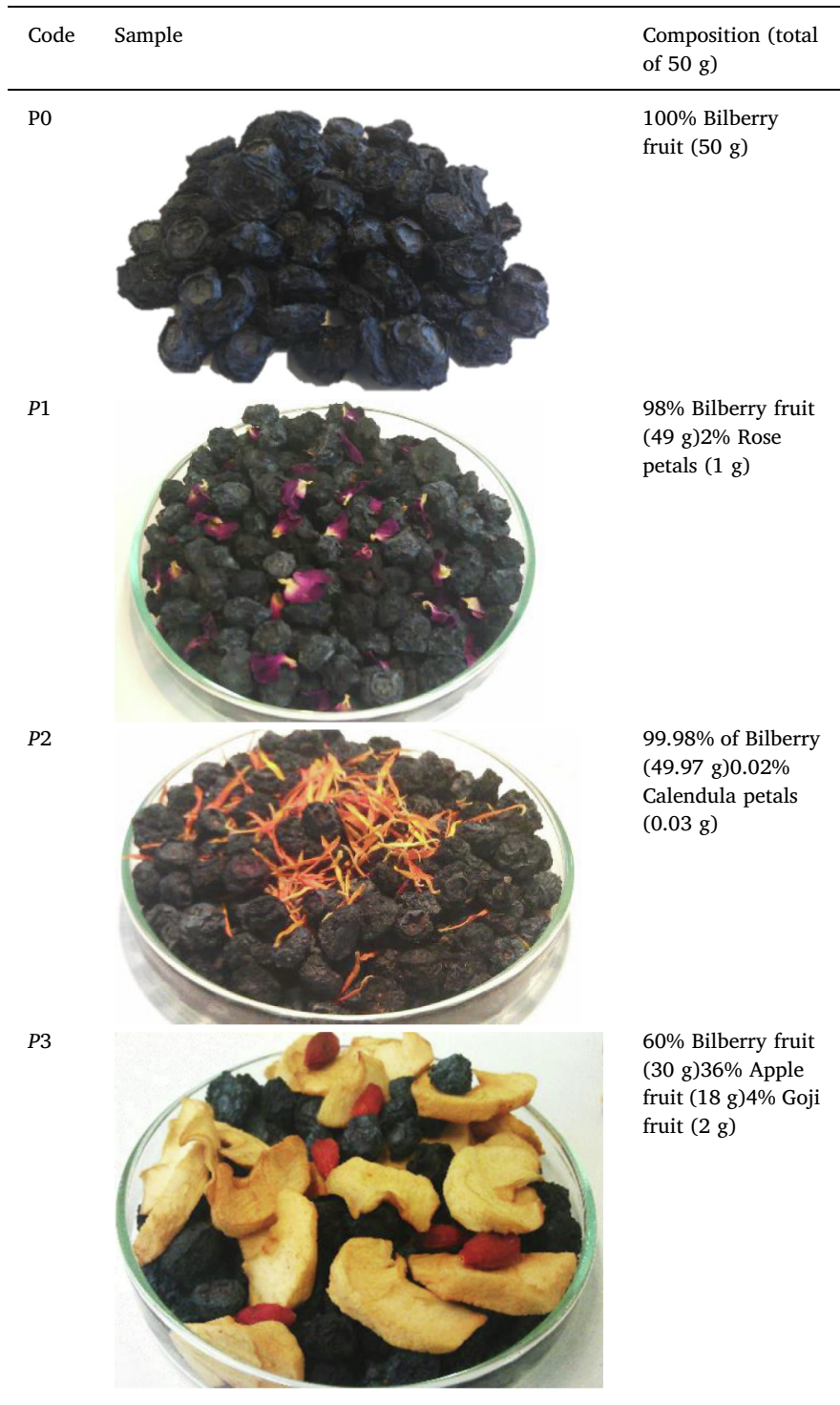

$100 \mathrm{~g})=100-(\mathrm{g}$ fat $+\mathrm{g}$ protein $+\mathrm{g}$ ash $)$. Additionally, the energetic value of the samples was calculated as follows: Energy (kcal/100 g) $=4$ $\times(\mathrm{g}$ proteins $+\mathrm{g}$ carbohydrates $)+9 \times(\mathrm{g}$ fat $)$.

\subsection{Chemical composition analysis}

The chemical composition studied consisted in the analysis of the content in fatty acids, tocopherols, soluble sugars, organic acids, and phenolic compounds.

The fatty acid faction was extracted of the powdered samples using a Soxhlet apparatus (obtain a lipid fraction and further trans-esterification) and the analysis was performed by gas chromatography coupled with a flame ionization detector (GC-FID; DANI model GC 1000 instrument, Contone, Switzerland). Results were expressed in relative percentage of each fatty acid (Dias et al., 2015).

The four vitamers of tocopherols were determined by HPLC (Knauer, Smartline system 1000, Berlin, Germany) coupled to a fluorescence detector (FP-2020; Jasco, Easton, MD, USA) (Dias et al., 2015), using tocol for the quantification as an internal standard. The results were expressed in $\mathrm{mg}$ per $100 \mathrm{~g}$ of dry weight.

Soluble sugars were determined by HPLC coupled to a refraction index detector (HPLC-RI); The quantification was performed using 
melezitose as an internal standard and the results were expressed in $g$ per $100 \mathrm{~g}$ of dry weight Dias et al. (2015).

The samples were also analyzed for their organic acids content by ultra-fast liquid chromatography coupled to photodiode array detector (UFLC-PDA; Shimadzu Coperation, Kyoto, Japan) (Dias et al., 2015). The quantification was performed from the peak areas recorded at $215 \mathrm{~nm}$ and by comparison with calibration curves obtained from each available organic acid. The results were expressed in $\mathrm{g}$ per $100 \mathrm{~g}$ of dry weight.

The phenolic profile was determined in the hydromethanolic extracts prepared by the following protocol: $1 \mathrm{~g}$ of each sample was extracted with $30 \mathrm{~mL}$ of methanol:water $(80: 20, v / v)$ at room temperature $\left(25{ }^{\circ} \mathrm{C}\right.$ ) and $150 \mathrm{rpm}$ during $1 \mathrm{~h}$, followed by filtration through a Whatman filter paper No. 4. Afterwards, the residue was re-extracted with an additional $30 \mathrm{~mL}$ portion of the hydromethanolic solution. Finally, the combined extracts were evaporated under reduced pressure (rotary evaporator Büchi R-210, Flawil, Switzerland) and the remaining aqueous extract was frozen, lyophilized and stored until further analysis. The phenolic profile (anthocyanins and non-anthocyanins compounds) was then determined by HPLC-DAD-ESI/MSn (Dionex Ultimate 3000 UPLC, Thermo Scientific, San Jose, CA, USA) in the hydromethanolic extract of $5 \mathrm{mg} / \mathrm{mL}$ following previously described procedures (Bessada, Barreira, Barros, Ferreira, \& Oliveira, 2016; Guimarães et al., 2013). The compounds detection was performed using a DAD (280, 330, 370, and $530 \mathrm{~nm}$ as preferred wavelengths) and a Linear Ion Trap LTQ XL mass spectrometer equipped with an ESI source (Thermo Finnigan, San Jose, CA, USA) working in negative mode (non-anthocyanins compounds) and positive mode (anthocyanin compounds). The identification was performed by comparison with standard compounds, when available. If no standard compound was available, phenolic compounds were identified based on their chromatographic behavior and UV-Vis and mass spectra and comparison with data reported in the literature. Quantification was made from the areas of the peaks by comparison with calibration curves obtained from standards. The results were expressed as $\mathrm{mg} / \mathrm{g}$ of extract.

\subsection{Evaluation of the bioactive properties}

All the performed assays for biological evaluation were carried out in the hydromethanolic extracts previously prepared.

The antioxidant activity was evaluated in the lyophilized extracts re-dissolved in methanol:water mixture (80:20 $v / v)$ through DPPH radical- scavenging activity, reducing power and inhibition of $\beta$-carotene bleaching in presence of linoleic acid, as described by Barros, Pereira, \& Ferreira (2013). Trolox was used as positive control and the results were expressed in $\mathrm{EC}_{50}$ values $(\mu \mathrm{g} / \mathrm{mL}$, extract concentration providing $50 \%$ of antioxidant activity).

The antibacterial activity was determined in the lyophilized extracts re-dissolved in culture medium (Muller-Hinton, $20 \mathrm{mg} / \mathrm{mL}$ ). The isolation of the microorganisms used occurred in patients hospitalized in the Local Health Unit of Bragança and Hospital Center of Trás-osMontes and Alto-Douro Vila Real, Northeast of Portugal. To determine the minimum inhibitory concentration (MIC), the Microdilution method and the rapid $p$-iodonitrotetrazolium chloride (INT) colorimetric assay were used (Kuete et al., 2011). Furthermore, three negative controls were prepared (one with MH/TSB, another one with the extract, and the third one with the medium, inoculum and antibiotic). Amikacin, tobramycin, amoxicillin/clavulanic acid and gentamicin were used as positive control strains for Gram-negative bacteria's, while ampicillin and linezolid were used for Gram-positive bacteria. The antibiotic susceptibility profile of all tested bacteria was previously screened by (Pires et al., 2018a).

Finally, the hepatotoxicity was determined in a cell culture (named as PLP2) established in our laboratory, as previously described by Pires et al. (2018a).

A freshly harvested porcine liver, obtained from a local slaughter house, was used in order to obtain the cell culture, designated as PLP2. The liver tissues were rinsed in Hank's balanced salt solution containing penicillin $(100 \mathrm{U} / \mathrm{mL})$ and streptomycin $(100 \mu \mathrm{g} / \mathrm{mL})$ and divided into $1 \times 1 \mathrm{~mm}^{3}$ explants. A few of these explants were transferred to tissue flasks $(25 \mathrm{~cm} 2)$ containing DMEM medium supplemented with fetal bovine serum (FBS, 10\%), nonessential amino acids ( $2 \mathrm{mM})$, penicillin $(100 \mathrm{U} / \mathrm{mL})$ and streptomycin $(100 \mathrm{mg} / \mathrm{mL})$, and incubated at $37{ }^{\circ} \mathrm{C}$ with a humidified atmosphere (5\% CO2). The medium was changed every two days and the cell cultivation was continuously monitored using a phase contrast microscope. When confluence was reached, the cells were sub-cultured and plated in 96-well plate (density of $1.0 \times 10^{4}$ cells/well) containing DMEM medium supplemented with FBS $(10 \%)$, penicillin $(100 \mathrm{U} / \mathrm{mL})$ and streptomycin $(100 \mu \mathrm{g} / \mathrm{mL})$ (Guimarães et al., 2013). The growth inhibition was evaluated using the SRB assay. Ellipticine was used as positive control and the results were expressed in $\mathrm{GI}_{50}$ values (concentration that inhibited $50 \%$ of the net cell growth).

\subsection{Statistical analysis}

All the assays were carry out in triplicate. Results were expressed as mean values and standard deviation (SD) and analyzed using one-way analysis of variance (ANOVA) followed by Tukey's HSD Test with $\alpha=0.05$. This analysis was carried out using IBM SPSS Statistics for Windows, Version 22.0. (IBM Corp., Armonk, New York, USA).

\section{Results and discussion}

\subsection{Nutritional value and chemical characterization}

As previously stated, the main objective of the present manuscript was to fully characterized three bilberry fruit based mixtures combined with rose petals $(P 1)$, calendula petals $(P 2)$, dehydrated apple and goji fruits ( $P 3)$, comparing all the results with a control sample containing only bilberry fruits (P0). It is important to indicate that rose and calendula petals, dehydrated apple and goji berries samples have already been studied individually by the authors regarding their nutritional profile and chemical content, as also for their bioactive potential (Pires et al., 2018a; Pires et al., 2018c; Pires et al., 2018b).

Data regarding the nutritional composition, fatty acids, soluble sugars, organic acids and tocopherols contents are shown in Table 2. Overall, despite the significant statistical differences between the four samples, the profiles were very similar, except for tocopherols content. As expected, carbohydrates were the most abundant macronutrient in all samples, ranging from 94.32 to $94.80 \mathrm{~g} / 100 \mathrm{~g} \mathrm{dw}$, followed by protein $(2.6 \pm 0.5$ to $3.7 \pm 0.6 \mathrm{~g} / 100 \mathrm{~g} \mathrm{dw})$, ash $(1.3 \pm 0.4$ to $1.6 \pm 0.1 \mathrm{~g} / 100 \mathrm{~g} \mathrm{dw})$ and fat $(0.7 \pm 0.04$ to $1.1 \pm 0.1 \mathrm{~g} / 100 \mathrm{~g} \mathrm{dw})$. There are already dehydrated fruit snacks on the market that have similar values in terms of energy supply and nutritional value in general, as is the example of the dehydrated apple of the brand Frubis (Fruta desidratada Archives - Frubis. (n.d.). Retrieved June 13, 2020), in which $100 \mathrm{~g}$ of dehydrated apple have $360 \mathrm{kcal}$. Meaning that in the developed snacks the nutritional profile obtained was very similar to what is already consumed in the market, using different edible fruits and flowers, all of them capable of a great nutritional, chemical and bioactive input, as described below.

Twenty-four fatty acids were identified, being polyunsaturated fatty acids (PUFA) predominant in all samples. To facilitate data analysis, only compounds with percentages higher than $2 \%$ are presented in Table 2. Linoleic acid (C18:2n6) was the major fatty acid found, followed by linolenic acid (C18:3n3) and oleic acid (C18:1n9). These results were in accordance with (Pires, Dias, Barros, \& Ferreira, 2017) regarding rose and calendula petals characterization. The great majority of the studies about linoleic acid and its derivatives show a direct/indirect link with inflammation and metabolic diseases, that makes it essential for human development (Choque, Catheline, Rioux, \& 
Table 2

Nutritional values, fatty acids profile, soluble sugars, organic acids and tocopherols in bilberry fruits (P0), combined with rose petals (P1), calendula petals (P2) and apple and goji berries $(P 3)$ (mean $\pm \mathrm{SD}$ ).

\begin{tabular}{|c|c|c|c|c|}
\hline & P0 & $P 1$ & $P 2$ & $P 3$ \\
\hline Fat & $1.1 \pm 0.3^{\mathrm{a}}$ & $1.1 \pm 0.2^{\mathrm{a}}$ & $0.8 \pm 0.1^{\mathrm{b}}$ & $0.70 \pm 0.04^{c}$ \\
\hline Proteins & $3.0 \pm 0.4^{c}$ & $4 \pm 1^{\mathrm{a}}$ & $3.0 \pm 0.2^{\mathrm{b}}$ & $3 \pm 1^{\mathrm{d}}$ \\
\hline Total available carbohydrates & $94.6 \pm 0.3^{\mathrm{c}}$ & $94.3 \pm 0.4^{\mathrm{c}}$ & $94.57 \pm 0.04^{\mathrm{b}}$ & $94.8 \pm 0.2^{\mathrm{a}}$ \\
\hline Energy (kcal/100 g) & $399 \pm 1^{\mathrm{a}}$ & $399.9 \pm 0.4^{\mathrm{a}}$ & $398 \pm 1^{\mathrm{b}}$ & $397.5 \pm 0.4^{\mathrm{b}}$ \\
\hline \multicolumn{5}{|c|}{ Fatty acids (relative percentage, $\%$ ) } \\
\hline C16:0 & $4.7 \pm 0.1^{\mathrm{c}}$ & $5.4 \pm 0.2^{\mathrm{b}}$ & $5 \pm 1^{\mathrm{b}}$ & $7 \pm 1^{\mathrm{a}}$ \\
\hline $\mathrm{C} 18: 2 \mathrm{n} 6$ & $42.1 \pm 0.2^{\mathrm{a}}$ & $40.8 \pm 0.3^{\mathrm{b}}$ & $41 \pm 1^{b}$ & $41.0 \pm 0.3^{\mathrm{b}}$ \\
\hline $\mathrm{C} 18: 3 \mathrm{n} 3$ & $32.9 \pm 0.2^{\mathrm{a}}$ & $32 \pm 1^{\mathrm{b}}$ & $32 \pm 1^{\mathrm{b}}$ & $30.9 \pm 0.4^{\mathrm{c}}$ \\
\hline SFA & $8.8 \pm 0.1^{\mathrm{c}}$ & $10 \pm 1^{\mathrm{b}}$ & $10 \pm 1^{b}$ & $11 \pm 1^{\mathrm{a}}$ \\
\hline MUFA & $16.00 \pm 0.01^{\mathrm{a}}$ & $15.7 \pm 0.1^{\mathrm{b}}$ & $15.9 \pm 0.3^{\mathrm{a}}$ & $15.7 \pm 0.2^{\mathrm{b}}$ \\
\hline PUFA & $75.3 \pm 0.1^{\mathrm{a}}$ & $74 \pm 1^{\mathrm{b}}$ & $74 \pm 1^{\mathrm{b}}$ & $73 \pm 1^{\mathrm{c}}$ \\
\hline \multicolumn{5}{|l|}{ Soluble sugars $(\mathrm{g} / 100 \mathrm{~g} \mathrm{dw})$} \\
\hline Fructose & $36 \pm 1^{\mathrm{a}}$ & $35.8 \pm 0.7^{\mathrm{a}}$ & $36.4 \pm 0.7^{\mathrm{a}}$ & $29.2 \pm 0.4^{\mathrm{b}}$ \\
\hline Quinic acid & $0.31 \pm 0.01^{\mathrm{a}}$ & $0.21 \pm 0.03^{\mathrm{c}}$ & $0.31 \pm 0.02^{\mathrm{a}}$ & $0.28 \pm 0.01^{\mathrm{b}}$ \\
\hline Malic acid & nd & $0.07 \pm 0.02^{\mathrm{b}}$ & $0.057 \pm 0.003^{\mathrm{c}}$ & $0.44 \pm 0.02^{\mathrm{a}}$ \\
\hline Shikimic acid & $0.003 \pm 0.001^{\mathrm{b}}$ & $0.002^{-} \pm 0.001^{\mathrm{c}}$ & $0.003 \pm 0.001^{\mathrm{a}}$ & $\operatorname{tr}-0.02$ \\
\hline Citric acid & $2.8 \pm 0.1^{\mathrm{b}}$ & $2.945 \pm 0.001^{\mathrm{a}}$ & $2.94 \pm 0.01^{\mathrm{c}}$ & $1.90 \pm 0.04^{c}$ \\
\hline Fumaric acid & $\operatorname{tr}$ & $\operatorname{tr}$ & $\operatorname{tr}$ & $\operatorname{tr}$ \\
\hline Sum & $3.15 \pm 0.04^{\mathrm{c}}$ & $3.30 \pm 0.05^{\mathrm{b}}$ & $3.37 \pm 0.01^{\mathrm{a}}$ & $2.67 \pm 0.01^{\mathrm{d}}$ \\
\hline \multicolumn{5}{|l|}{ Tocopherols (mg/100 g dw) } \\
\hline$\alpha$-Tocopherol & $1.8 \pm 0.1^{\mathrm{c}}$ & $2.0 \pm 0.1^{\mathrm{b}}$ & $4.7 \pm 0.1^{\mathrm{a}}$ & $1.3 \pm 0.1^{\mathrm{d}}$ \\
\hline$\beta$-Tocopherol & nd -0.1 & $0.004 \pm 0.001^{\mathrm{b}}$ & $0.070 \pm 0.003^{\mathrm{a}}$ & nd -0.1 \\
\hline$\gamma$-Tocopherol & $1.185 \pm 0.004^{\mathrm{b}}$ & $1.176 \pm 0.004^{\mathrm{b}}$ & $1.5 \pm 0.1^{\mathrm{a}}$ & $0.715 \pm 0.003^{c}$ \\
\hline$\delta$-Tocopherol & nd & $0.0030 \pm 0.0001$ & nd & nd \\
\hline Sum & $3.04 \pm 0.12^{\mathrm{c}}$ & $3.2 \pm 0.1^{\mathrm{b}}$ & $6.301 \pm 0.003^{\mathrm{a}}$ & $2.0 \pm 0.1^{\mathrm{d}}$ \\
\hline
\end{tabular}

The results are expressed on fresh weight basis, dw- dry weight basis; nd- not detected C10:0- Capric acid; C12:0- Lauric acid; C14:0- Myristic acid; C14:1 - Myristoleic acid; C15:0- Pentadecanoic acid; C16:0- Palmitic acid; C16:1 - Palmitoleic acid; C17:0 - Heptadecanoic acid; C18:0 - Stearic acid; C18:1n9- Oleic acid; C18:2n6Linoleic acid; C18:3n3- Linolenic acid; C20:0- Arachidic acid; C20:1-Eicosenoic acid; C20:2-Eicosadienoic acid; C20:3n6 - Eicosatrienoic acid; C20:4n6- Arachidonic acid; C20:3n3- Eicosatrienoic acid; C20:5n3- Eicosapentaenoic acid; C22:0 - Behenic acid; C22:1n9- Erucic acid; C22:2- Docosadienoic acid; C23:0 - Tricosanoic acid; C24:0 - Lignoceric acid. SFA- saturated fatty acids, MUFA- monounsaturated fatty acids, PUFA- polyunsaturated fatty acids. Standard calibration curves used for the quantification of organic acids: : oxalic acid $\left(\mathrm{y}=45973+9 \times 10^{6} \mathrm{x}, \mathrm{R}^{2}=0.9901\right)$; quinic acid $\left(\mathrm{y}=46061+610607 \mathrm{x}, \mathrm{R}^{2}=0.9995\right)$; malic acid $\left(y=92665+912441 x, R^{2}=0.9991\right)$; citric acid $\left(y=45682+1 \times 10^{6} x, R^{2}=0.9997\right)$, and succinic acid $\left(y=50689+592888 x, R^{2}=0.9996\right)$. In each row different letters mean significant differences between samples $(\mathrm{p}<0.05)$, where "a" and "d" correspond to the highest and lowest values, respectively

Legrand, 2014). Comparing the results obtained for the fatty acids between the individual samples already studied by the authors and the mixtures now analyzed, it was expected that there would be a higher concentration of linoleic acid in the mixtures containing rose and goji, $\alpha$-linolenic and palmitic acid in mixtures with calendula (Pires, Dias, Barros, \& Ferreira, 2017) and apple (Pires et al., 2018a), respectively. However, the amounts of rose and calendula petals, goji or apple in the mixtures seemed not sufficient to cause relevant differences in fatty acid distribution in $P 1, P 2$, and $P 3$ when compared to P0.

Regarding sugar content, fructose, glucose and sucrose were detected in all samples, being fructose the most abundant one $(29.2 \pm 0.4$ to $36.4 \pm 0.7 \mathrm{~g} / 100 \mathrm{~g} \mathrm{dw})$. Similar values were reported by Mikulic-Petkovsek et al. (2015) in fruits of $V$. myrtillus where fructose was the most abundant sugar. The addition of the different components did not induce significant differences in sugar contents in mixtures $P 1$ and $P 2$ when compared to P0, but significant lower contents were found in $P 3$ (added with apple and goji fruits), which could be attributed to the lower proportion of bilberry in $P 3$ sample.

The profile in organic acids was similar in all samples, being identified six main compounds. The main organic acid found was citric, followed by quinic acid; fumaric acid was in trace amounts in all four samples. Malic acid was not found in P0 sample, contrary to what happens in the other three samples. This was a expectable result, since malic acid was previously described in rose and calendula petals ( $P 1$ and $P 2$, respectively, (Pires, Dias, Barros, \& Ferreira, 2017) and apple (P3) samples (Pires et al., 2018a). As for sugars, significant lower organic acid content was found in $P 3$ compared to P0 and the other mixtures.

Regarding tocopherols, significant differences among the four samples were determined, probably due to their perishability and the different profiles of the individual components. $\alpha$-Tocopherol was the most abundant isoform in all samples (ranging from $1.31 \pm 0.08$ to $4.74 \pm 0.05 \mathrm{mg} / 100 \mathrm{~g} \mathrm{dw}) . P 1$ was the only sample that presented the four isoforms in its composition due to their presence in rose petals, as previously reported by (Pires, Dias, Barros, \& Ferreira, 2017), and similarly happens in $P 2$ for the presence of $\beta$-tocopherol (absent in P0 sample) and the significant increase in the amount of $\alpha$-tocopherol, due to the presence of calendula petals (Pires, Dias, Barros, \& Ferreira, 2017). It was also in $P 2$ samples that it was observed the highest amount of total tocopherol content $(6.301 \mathrm{mg} / 100 \mathrm{~g} \mathrm{dw})$, once again attributed to the presence of calendula edible flowers. The presence of apple and goji fruits in $P 3$ mixtures had no influence on the tocopherols profile, although there was a decrease in their total content $(2.02 \pm 0.08 \mathrm{mg} / 100 \mathrm{~g} \mathrm{dw})$ compared to P0 $(3.04 \pm 0.12 \mathrm{mg} / 100 \mathrm{~g}$ $\mathrm{dw}$ ), which could be newly associated to the lower proportion of bilberry in this sample. 


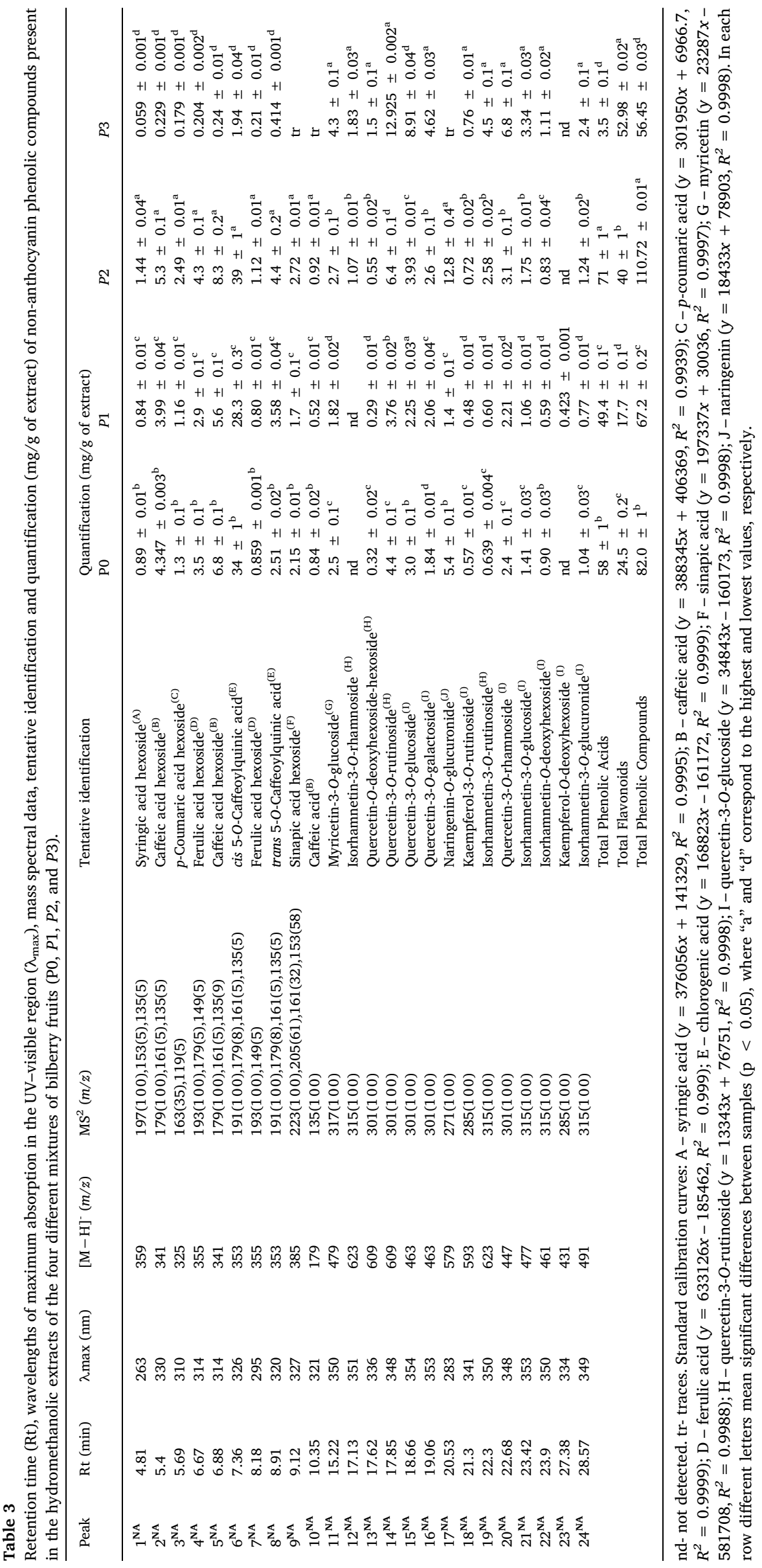




\subsection{Non-anthocyanin and anthocyanin phenolic profile}

Data obtained from the HPLC-DAD-ESI/MS analysis of the non-anthocyanin phenolic compounds in the hydromethanolic extracts of the four different mixtures are presented in Table 3. Twenty-four different phenolic compounds were found, from which ten phenolic acids derivatives (peaks $\mathbf{1}^{\mathrm{NA}}$ to $10^{\mathrm{NA}}$ ) and fourteen flavonoids (peaks $11^{\mathrm{NA}}$ to $24^{\mathrm{NA}}$ ), including thirteen flavonol and one flavanone glycosides.

Flavonols were the major class of phenolic compounds found in bilberry fruits, derived from quercetin isorhamnetin, kaempferol and myricetin. Peaks $11^{\mathrm{NA}}$ (myricetin-3-O-glucoside), $\mathbf{1 4}^{\mathrm{NA}}$ (quercetin-3-Orutinoside), $\mathbf{1 5}^{\mathrm{NA}}$ (quercetin-3-O-glucoside), $\mathbf{1 8}^{\mathrm{NA}}$ (kaempferol-3-O-rutinoside), $19^{\mathrm{NA}}$ (isorhamnetin-3-O-rutinoside), and $\mathbf{2 1}^{\mathrm{NA}}$ (isorhamnetin-3-O-glucoside) were positively identified from their elution time (Rt) and UV and mass spectra in comparison to commercial standards. Peak $13^{\mathrm{NA}}$ presented similar characteristics as peak $14^{\mathrm{NA}}$ $\left([\mathrm{M}-\mathrm{H}]^{-}\right.$at $\left.m / z 609\right)$ but a different Rt, so that it was tentatively assigned as a quercetin- $O$-deoxyhexoside-hexoside. Peak $16^{\text {NA }}\left([\mathrm{M}-\mathrm{H}]^{-}\right.$ at $m / z 463)$ and peak $20^{\mathrm{NA}}\left([\mathrm{M}-\mathrm{H}]^{-}\right.$at $\left.m / z 447\right)$ presented the aglycone fragment of quercetin $(\mathrm{m} / \mathrm{z}$ at 301$)$ from the losses of an hexosyl and deoxyhexosyl moieties. Taking into account the previously compounds reported in V. myrtillus (Mikulic-Petkovsek, Slatnar, Stampar, \& Veberic, 2012; Vrhovsek, Masuero, Palmieri, \& Mattivi, 2012; Diaconeasa, Florica, Rugină, Lucian, \& Socaciu, 2014), they were tentatively assigned as quercetin-3-O-galactoside (compound $16^{\mathrm{NA}}$ ) and quercetin-3-O-rhamnoside $\left(\mathbf{2 0}^{\mathrm{NA}}\right)$. Similarly, peak $23^{\mathrm{NA}}\left([\mathrm{M}-\mathrm{H}]^{-}\right.$at $m$ / $z$ 431) revealed a unique $\mathrm{MS}^{2}$ fragment at $m / z 285$, corresponding to the loss of a deoxyhexosyl moiety, being tentatively identified as kaempferol-O-deoxyhexoside.

The $O$-methylated form of quercetin (isorhamnetin) was also found abundantly in all four samples. Peaks $\mathbf{1 2}^{\mathrm{NA}}\left([\mathrm{M}-\mathrm{H}]^{-}\right.$at $\left.m / z 623\right), \mathbf{2 2}^{\mathbf{N A}}$ $\left([\mathrm{M}-\mathrm{H}]^{-}\right.$at $\left.m / z 461\right)$, and $24^{\mathrm{NA}}\left([\mathrm{M}-\mathrm{H}]^{-}\right.$at $\left.m / z 491\right)$ presented a unique $\mathrm{MS}^{2}$ fragment at $m / z 315$ (isorhamnetin aglycone), being tentatively identified as isorhamnetin-O-deoxyhexosyl-hexoside, isorhamnetin-O-deoxyhexoside and isorhamnetin- $O$-glucuronide, respectively. The presence of isorhamnetin-3-O-rutinoside and isorhamnetin3-O-glucuronide, which may correspond to peaks $12^{\mathrm{NA}}$ and $24^{\mathrm{NA}}$, has been reported by Mikulic-Petkovsek et al. (2012) in different berries.

Phenolic acids were the second main group of compounds found in the hydromethanolic extracts of bilberry, being the majority of them linked to sugar moieties, such as peaks $\mathbf{1}^{\mathrm{NA}}$ (syringic acid hexoside, $[\mathrm{M}-\mathrm{H}]^{-}$at $m / z 359$ ), peak $2^{\mathrm{NA}} / 5^{\mathrm{NA}}$ (caffeic acid hexoside $[\mathrm{M}-\mathrm{H}]^{-}$at $m / z 341$ ), $3^{\mathrm{NA}}$ (p-coumaric acid hexoside, $[\mathrm{M}-\mathrm{H}]^{-}$at $\left.m / z 325\right), 4^{\mathrm{NA}}$ / $7^{\mathrm{NA}}$ (ferulic acid hexoside, $[\mathrm{M}-\mathrm{H}]^{-}$at $m / z 355$ ), and $9^{\mathrm{NA}}$ (sinapic acid hexoside, $[\mathrm{M}-\mathrm{H}]^{-}$at $\left.m / z 385\right)$. Peak $10^{\mathrm{NA}}$ was positively identified as caffeic acid according to its UV spectra, elution order, and fragmentation pattern in comparison to a commercial standard. Peaks $\mathbf{6}^{\mathbf{N A}}$ and $8^{\mathrm{NA}}$ were tentatively identified as cis and trans 5-O-caffeoylquinic acid, respectively, accordingly to their characteristic UV spectra, maximum wavelength around 320-326 nm, fragmentation pattern and elution order, by comparison with our database library. Peak $6^{\mathrm{NA}}$ was the main phenolic acid found in all four samples.

Finally, one flavanone was tentatively identified as naringenin- $O$ glucuronide (peak $17^{\mathrm{NA}},[\mathrm{M}-\mathrm{H}]^{-}$at $m / z 579$ ), with an $\mathrm{MS}^{2}$ fragment at $\mathrm{m} / z 271$ (naringenin aglycone) that corresponded to the loss of a glucuronyl unit. Its UV spectrum was also coherent with that of a flavanone. This was the second main compound found in $P 2$ samples $(12.78 \mathrm{mg} / \mathrm{g}$ of extract), being found in trace amounts in $P 3$ samples. As far as the authors knowledge this is the first that naringenin glycosylated derivatives is reported in bilberry fruits.

In addition to the previously cited authors, most of the detected compounds (either flavonols and phenolic acid derivatives) have been previously reported in V. myrtillus fruits by other authors (e.g., Babova, Occhipinti, Capuzzo, \& Maffei, 2016; Bujor, Le Bourvellec, Volf, Popa, \& Dufour, 2016). Some authors also reported the presence of such compounds in the foliar tissues and leaves/stems of V. myrtillus (Bujor et al., 2016; Ieri, Martini, Innocenti, \& Mulinacci, 2013).

As it can be seen in Table 3, there is no phenolic compound that stands out in $P 1, P 2$, and $P 3$ mixtures in comparison to the P0 sample. The profile of the four samples is very similar, leading to the conclusion that the phenolic compounds present in bilberries fruits are predominant to those of other elements present in the mixtures. Except for peak 23 (kaempferol-O-deoxyhexoside), only detected in $P 1$, previously reported in the same rose petals sample by Pires et al. (2018c)Pires et al., 2018b. In the $P 2$ mixture, seven of the identified compounds (caffeic acid hexoside, 5-O-caffeoylquinic acid, caffeic acid, quercetin$O$-deoxyhexoside-hexoside, quercetin-3-O-rutinoside, isorhamnetin-3$O$-rutinoside, and isorhamnetin-3-O-glucoside) are very common in bilberries fruits, but also in calendula flowers (Pires et al., 2018c; Pires et al., 2018b). In the case of the $P 3$ mixture, none of the identified compounds were in common with the apple phenolic compounds, previously identified by Pires et al. (2018a). As for goji fruits, six identified compounds ( $p$-coumaric acid hexoside, 5-O-caffeoylquinic acid, sinapic acid hexoside, quercetin-3-O-rutinoside, quercetin-3-Ogalactoside, and quercetin-3-O-glucoside) were in common with bilberry fruits (Pires et al., 2018b). There was a statistically significant increase in the case of quercetin-3-O-rutinoside $(12.925 \pm 0.002 \mathrm{mg} / \mathrm{g}$ in $P 3$ and only $4.4 \pm 0.1 \mathrm{mg} / \mathrm{g}$ in $\mathrm{P} 0$ ), which can be explained by the fact that this compound has been identified as the major phenolic compounds in goji fruits (Pires et al., 2018b). Overall, the $P 2$ sample revealed the highest content of total phenolic compounds (110.72 $\pm 0.01 \mathrm{mg} / \mathrm{g}$ of extract), and accordingly, the common compounds between bilberries and calendula flowers are all in higher quantities than in P0 sample. Therefore, it can be concluded that, despite their low concentration in the mixture, calendula flowers provide relevant amounts of phenolic compounds to this mixture, which may be of great interest for the final consumer.

The anthocyanin compounds present in the hydromethanolic extracts in all the analysed mixtures (P0, $P 1, P 2$, and $P 3$ ) are presented in Table 4. Up to twenty different anthocyanin glycosides were identified derived from six anthocyanidins (cyanidin, delphinidin, malvidin, pelargonidin, peonidin, and petunidin). The major group of anthocyanins were the glycosylated derivatives of pelargonidin, in which six compounds were detected, all of them in the sample $P 3$, whose anthocyanin profile is completely different to the other three mixtures, denoting that its anthocyanin composition does not derive from blueberry but rather from goji fruits. Actually, no pelargonidin derivatives were found in the blueberry sample (P0) and its mixtures with rose and calendula flowers ( $P 1$ and $P 2$ ). Similar to what happened with non-anthocyanin phenolic compounds, the profile of anthocyanin compounds in $V$. myrtillus fruits has already been extensively studied (e.g., Babova et al., 2016; Može et al., 2011; Pires, Caleja, Santos-Buelga, Barros, \& Ferreira, 2020).

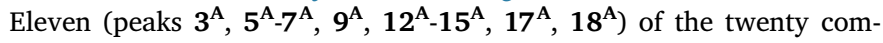
pounds identified were previously reported by the authors in $V$. myrtillus (Pires et al., 2020). The remaining nine anthocyanins were found in mixture P3. Thus, peaks $11^{\mathrm{A}}\left([\mathrm{M}+\mathrm{H}]^{+}\right.$at $\left.\mathrm{m} / \mathrm{z} 433\right)$ and $\mathbf{2 0}^{\mathrm{A}}$ $\left([\mathrm{M}+\mathrm{H}]^{+}\right.$at $m / z$ 519) corresponded to pelargonidin derivatives, presenting a characteristic absorption spectra and a unique $\mathrm{MS}^{2}$ fragment at $m / z 271$, coherent with the loss of hexosyl and malonyl-hexosyl moieties, being tentatively identified as, pelargonidin- $O$-hexoside and pelargonidin-O-malonylhexoside, respectively. Peak $2^{\mathbf{A}}\left([\mathrm{M}+\mathrm{H}]^{+}\right.$at $m / z 595)$ presented an additional hexosyl moiety, compared to peak $\mathbf{1 1}^{\mathrm{A}}$, being tentatively identified as pelargonidin-O-dihexoside. Peaks $\mathbf{8}^{\mathrm{A}} / \mathbf{1 0}^{\mathrm{A}}\left([\mathrm{M}+\mathrm{H}]^{+}\right.$at $\left.m / z 681\right)$ and $16^{\mathrm{A}}\left([\mathrm{M}+\mathrm{H}]^{+}\right.$at $m / z$ 767) were tentatively assigned as pelargonidin-malonyl-dihexoside and pelargonidin-dimalonyl-dihexoside, respectively. Cyanidin derivatives were the second group of anthocyanins found in the mixtures. Peak $19^{\mathrm{A}}$ $\left([\mathrm{M}+\mathrm{H}]^{+}\right.$at $\left.m / z 535\right)$ presented a unique $\mathrm{MS}^{2}$ fragment at $m / z 287$, which corresponded to the loss of a malonyl-hexosyl moiety, being tentatively identified as cyanidin-malonyl-hexoside. Peak $\mathbf{1}^{\mathrm{A}}$ $\left([\mathrm{M}+\mathrm{H}]^{+}\right.$at $\left.m / z 611\right)$ presented the consecutive release of two hexosyl moieties, being tentatively identified as cyanidin-3,5-O- 


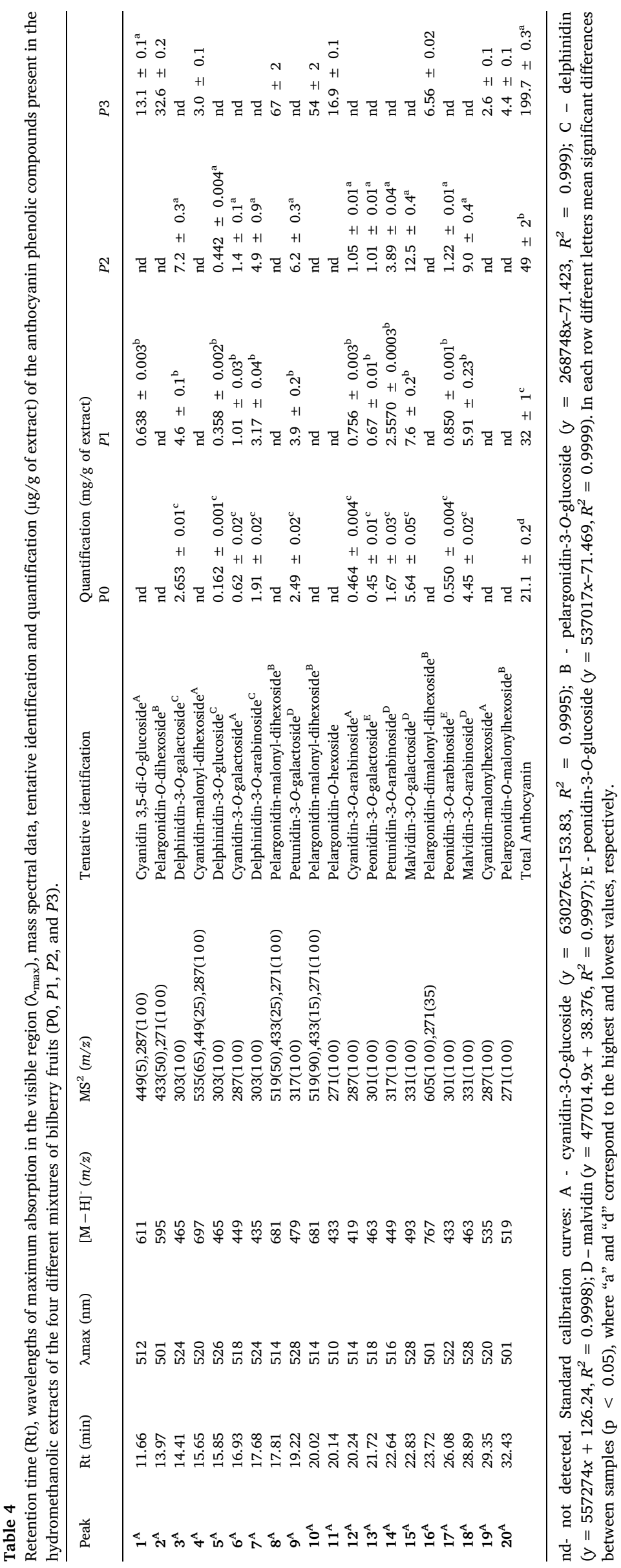


diglucoside, an anthocyanin detected in rose and centaurea (Pires et al., 2018d) flowers, components of mixtures $P 1$ and $P 3$, where the compound was detected. Peak $4^{\mathrm{A}}\left([\mathrm{M}+\mathrm{H}]^{+}\right.$at $m / z$ 697) presented $\mathrm{MS}^{2}$ fragments at $m / z 535,449$, and 287 which corresponded to the loss of $162 \mathrm{u}$ (hexose), $86 \mathrm{u}$ (malonyl), and $162 \mathrm{u}$ (hexose), respectively, being tentatively identified as cyanidin-malonyl-dihexoside.

As above indicated, the anthocyanin profile in the mixture $P 3$ samples greatly differs from the other three samples, in fact, none of the anthocyanins found in $P 3$ was detected in them (but for peak $\mathbf{1}^{\mathrm{A}}$ in $P 1$ ), which is explained for goji fruits (and apple in less extent) being the main contributors to their anthocyanin composition; it should also be taken into account that proportion of bilberries in $P 3$ is lower than in the other mixtures. On the other hand, it is common knowledge that apples have a relatively very low $\mathrm{pH}$ value (Li et al., 2013), which could be influencing the extraction of anthocyanins, having already been proven that at lower $\mathrm{pH}$ values the extraction of these type of compounds increases. The possible creation of a microenvironment with low $\mathrm{pH}$ values and compounds that stabilize anthocyanins may be the explanation for the higher concentration $(199.7 \pm 0.3 \mathrm{mg} / \mathrm{g}$ of extract), but also for the different profile, of anthocyanins in $P 3$, as it may help to extract compounds attached to matrix structures that are, therefore, less available in a conventional extraction. It is also possible to verify, although it is not as significant, that $P 1$ and $P 2$ extracts also possess greater amounts of anthocyanin compounds $(32.2 \pm 0.5$ and $49 \pm 2 \mathrm{mg} / \mathrm{g}$, respectively) than P0 (21.1 $\pm 0.2 \mathrm{mg} / \mathrm{g})$. Calendula flowers do not have anthocyanins in its composition, so that this component shows no influence the anthocyanin profile of the mixture. Mixture $P 1$ has a very similar profile to $\mathrm{P} 0$, with the exception of peak $\mathbf{1}^{\mathrm{A}}$ (cyanidin 3,5-di-O-glucoside), which was not detected in P0. Thus the presence of this anthocyanin was already expected, since it is the major anthocyanin compound found in rose flowers (Pires et al., 2018d).

\subsection{Bioactivity assessment}

Data regarding the antioxidant, antibacterial, and hepatotoxicity activities of the hydromethanolic extracts of P0, $P 1, P 2$ and $P 3$ are shown in Table 5. $P 2$ sample was the one that presented the lowest $\mathrm{EC}_{50}$ values for the antioxidant assays performed, namely DPPH scavenging activity, and $\beta$-carotene bleaching inhibition $\left(\mathrm{EC}_{50}=2.38\right.$ and $0.93 \mathrm{mg} / \mathrm{mL}$, respectively). The differences between P0 and $P 1$ samples (considering that the differences in the bilberry fruits quantity were not significant) may be due to the presence of rose samples, that, as previously described, presented a very good antioxidant potential (Pires et al., 2018c; Pires et al., 2018b). On the contrary, P3 sample was the one that presented the highest $\mathrm{EC}_{50}$ values (lowest antioxidant potential), which could be due to the lowest amount of bilberry fruits and the relatively low activity conferred by the apple and goji fruits samples. Comparing the previously described results for the antioxidant activity of rose, calendula (Pires et al., 2018c; Pires et al., 2018b), apple (Pires, et al., 2018a) and goji fruits (Pires et al., 2018b), it was observed that the rose sample presented the lowest $\mathrm{EC}_{50}$ values, being therefore in agreement with the results herein obtained.

Regarding the antibacterial activity, the best results were found against Gram-positive bacteria, showing the lowest MIC values (ranging from 2.5 and $5 \mathrm{mg} / \mathrm{mL}$ ) in all the four studied samples. The highest concentration of bilberry fruits in P0 and $P 1$ sample could be the reason to the higher antibacterial activity described. However, in $P 3$, despite having a lower amount of bilberry, the presence of apples and goji fruits (previously described by the authors, as also having antibacterial activity) could have contributed to the equal antibacterial results obtained $(2.5 . \mathrm{mg} / \mathrm{mL}) . P 2$ also showed MIC values of $2.5 \mathrm{mg} / \mathrm{mL}$ against the Gram-negative bacteria Escherichia coli extended spectrum $\beta$-lactamases (ESBL 1 and ESBL 2), and $5 \mathrm{mg} / \mathrm{mL}$ against E. coli and Morganella morganii. These results were in agreement with those reported by Pires et al. (2018c)Pires et al., 2018b, that showed rose petals are very active against $E$. coli, although presenting lower MIC values when considered alone $(1.25 \mathrm{mg} / \mathrm{mL})$. The previous works performed by the authors (Pires et al., 2018a; Pires et al., 2018b; Pires et al., 2018c) also revealed that the edible flowers, apple and goji fruits were most active against Gram-positive bacteria's, with MIC values ranging from of 1.25 to $10 \mathrm{mg} / \mathrm{mL}$ for edible petals, 2.5 to $5 \mathrm{mg} / \mathrm{mL}$ for goji fruits, and 2.5 to $5 \mathrm{mg} / \mathrm{mL}$ for apple samples.

Regarding the hepatotoxic assays, none of extracts showed hepatotoxicity against the non-tumor PLP2 cell line studied, demonstrating the non-toxicity of these snacks for later human consumption was

Table 5

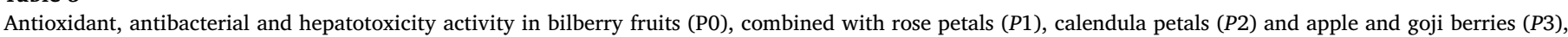
(mean $\pm \mathrm{SD}$ ).

\begin{tabular}{|c|c|c|c|c|}
\hline & P0 & $P 1$ & $P 2$ & $P 3$ \\
\hline \multicolumn{5}{|c|}{ Antioxidant activity ${ }^{\mathrm{A}} \mathrm{EC}_{50}$ values $(\mathrm{mg} / \mathrm{mL})$} \\
\hline DPPH scavenging activity & $2.95 \pm 0.03^{\mathrm{b}}$ & $2.5 \pm 0.1^{\mathrm{c}}$ & $2.38 \pm 0.04^{\mathrm{d}}$ & $3.9 \pm 0.1^{\mathrm{a}}$ \\
\hline Reducing power & $1.10 \pm 0.02^{\mathrm{d}}$ & $1.15 \pm 0.03^{\mathrm{c}}$ & $1.20 \pm 0.02^{\mathrm{b}}$ & $1.59 \pm 0.01^{\mathrm{a}}$ \\
\hline$\beta$-carotene bleaching inhibition & $2.07 \pm 0.04^{\mathrm{b}}$ & $1.6 \pm 0.1^{\mathrm{c}}$ & $0.93 \pm 0.01^{\mathrm{d}}$ & $3.60 \pm 0.04^{\mathrm{a}}$ \\
\hline \multicolumn{5}{|c|}{ Antibacterial activity ${ }^{\mathrm{B}}$ MIC values (mg/mL) } \\
\hline \multicolumn{5}{|l|}{ Gram-negative bacteria } \\
\hline Acinetobacter baumanii & $>20$ & 20 & $>20$ & $>20$ \\
\hline Escherichia coli ESBL1 & 5 & 2.5 & 5 & 5 \\
\hline Escherichia coli ESBL2 & 2.5 & 2.5 & 2.5 & 2.5 \\
\hline Escherichia coli & 5 & 5 & 5 & 5 \\
\hline Klebsiella pneumoniae & 20 & 20 & 10 & 20 \\
\hline Klebsiella Pneumoniae ESBL & $>20$ & $>20$ & 20 & 20 \\
\hline Morganella morganii & 5 & 5 & 5 & 5 \\
\hline \multicolumn{5}{|l|}{ Gram-positive bacteria } \\
\hline Enterococcus faecalis & 2.5 & 2.5 & 2.5 & 2.5 \\
\hline Listeria monocytogenes & 2.5 & 2.5 & 2.5 & 2.5 \\
\hline Staphylococcus aureus & 2.5 & 2.5 & 5 & 2.5 \\
\hline MRSA & 2.5 & 2.5 & 5 & 2.5 \\
\hline$M S S A$ & 2.5 & 2.5 & 5 & 2.5 \\
\hline \multicolumn{5}{|l|}{ Hepatotoxicity $\mathrm{GI}_{50}$ values $(\mu \mathrm{g} / \mathrm{mL})$} \\
\hline PLP2 & $>400$ & $>400$ & $>400$ & $>400$ \\
\hline
\end{tabular}

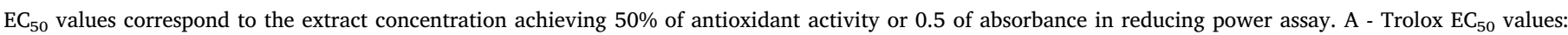

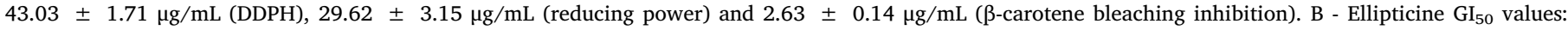

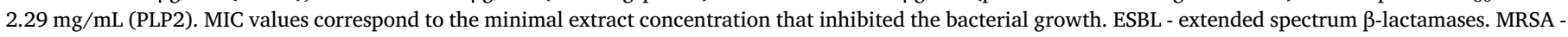
Methicillin-resistant Staphylococcus aureus. MSSA - Methicillin-susceptible Staphylococcus aureus 
observed.

Overall, the dry bilberry fruits revealed to possess a good nutritional composition with low fat content, and high carbohydrates and energy contribution. However, when supplemented with other plant matrices, they increased their protein content and bioactive potential, as observed in the mixture with rose petals (sample $P 1$ ). The supplementation with calendula petals ( $P 2$ sample) led to higher contents in organic acids, tocopherols (mainly $\alpha$-tocopherol), phenolic acid derivatives, and total non-anthocyanin phenolic compounds (mainly due to the presence of 5-O-caffeoylquinic acid and naringenin-O-glucuronide). Regarding the mixture of bilberry with apple and goji fruits (sample $P 3$ ), an overall loss of several nutritional, chemical and bioactive properties was produced when compared to the control sample P0, although it shows a very different anthocyanin profiles and an increase in total anthocyanin content by 9-fold compared to P0. The lower proportion of bilberry in this mixture in favor of apple and goji fruits and its lower $\mathrm{pH}$ value, which may provide higher anthocyanin extractability, could be the main contributing factors to its different anthocyanin composition.

The present study contributes to support the interest of formulating bilberry-based snacks supplemented with other plant matrices, such as edible petals or fruits, as an asset for consumers, not only regarding their nutritional and phytochemical input, but also by their improved bioactive properties.

Although the fruits and flowers generally exhibit a pleasant taste, sensory characteristics presented by these new food products, may put into question the acceptability by the final consumers. As such, as future work, sensory analyzes will be carried out, using a panel of trained tasters, to evaluate the acceptance of these new food products.

\section{CRediT authorship contribution statement}

Tânia C.S.P. Pires: Methodology, Investigation, Formal analysis, Writing - original draft. Maria Inês Dias: Methodology, Investigation, Formal analysis, Writing - original draft. Ricardo C. Calhelha: Methodology. Maria José Alves: Methodology, Formal analysis. Celestino Santos-Buelga: Conceptualization, Methodology, Funding acquisition, Writing - review \& editing. Isabel C.F.R. Ferreira: Conceptualization, Methodology, Funding acquisition, Project administration, Writing - review \& editing. Lillian Barros: Conceptualization, Methodology, Investigation, Formal analysis, Project administration, Writing - review \& editing.

\section{Declaration of Competing Interest}

The authors declare that they have no known competing financial interests or personal relationships that could have appeared to influence the work reported in this paper.

\section{Acknowledgements}

The authors are grateful to the Foundation for Science and Technology (FCT, Portugal) for financial support through national funds FCT/MCTES to CIMO (UIDB/00690/2020); national funding by FCT, P.I., through the institutional scientific employment programcontract for M.I. Dias, R.C. Calhelha and L. Barros contracts; individual PhD fellowship for Tânia Pires (SFRH/BD/129551/2017); to the European Structural and Investment Funds (FEEI) through the Regional Operational Program North 2020, within the scope of project Mobilizador ValorNatural ${ }^{\oplus}$; and to FEDER-Interreg España-Portugal programme for financial support through the project 0377_Iberphenol_6_E and TRANSCoLAB 0612_TRANS_CO_LAB_2_P. The GIP-USAL is financially supported by the Spanish Government through the project AGL2015-64522-C2-2-R.

\section{References}

AOAC (2016). Official Methods of Analysis of AOAC international. The Association of Official Analytical Chemists International.

Babova, O., Occhipinti, A., Capuzzo, A., \& Maffei, M. E. (2016). Extraction of bilberry (Vaccinium myrtillus) antioxidants using supercritical/subcritical CO2 and ethanol as co-solvent. Journal of Supercritical Fluids, 107, 358-363.

Barros, L., Pereira, C., \& Ferreira, I. C. F. R. (2013). Optimized Analysis of Organic Acids in Edible Mushrooms from Portugal by Ultra Fast Liquid Chromatography and Photodiode Array Detection. Food Analytical Methods, 6(1), 309-316.

Bessada, S. M. F., Barreira, J. C. M., Barros, L., Ferreira, I. C. F. R., \& Oliveira, M. B. P. P. (2016). Phenolic profile and antioxidant activity of Coleostephus myconis (L.) Rchb.f.: An underexploited and highly disseminated species. Industrial Crops and Products, 89, 45-51. https://doi.org/10.1016/j.indcrop.2016.04.065.

Bujor, O. C., Le Bourvellec, C., Volf, I., Popa, V. I., \& Dufour, C. (2016). Seasonal variations of the phenolic constituents in bilberry (Vaccinium myrtillus L.) leaves, stems and fruits, and their antioxidant activity. Food Chemistry, 213, 58-68.

Choque, B., Catheline, D., Rioux, V., \& Legrand, P. (2014). Linoleic acid: Between doubts and certainties. Biochimie, 96(1), 14-21. https://doi.org/10.1016/j.biochi.2013.07. 012 .

Diaconeasa, Z., Florica, R., Rugină, D., Lucian, C., \& Socaciu, C. (2014). HPLC/PDA-ESI/ MS Identification of Phenolic Acids, Flavonol Glycosides and Antioxidant Potential in Blueberry, Blackberry, Raspberries and Cranberries. Journal of Food and Nutrition Research, 2(11), 781-785.

Dias, M. I., Barros, L., Morales, P., Sánchez-Mata, M. C., Oliveira, M. B. P. P., \& Ferreira, I. C. F. (2015). Nutritional parameters of infusions and decoctions obtained from Fragaria vesca L. roots and vegetative parts. LWT - Food Science and Technology, 62(1), 32-38. https://doi.org/10.1016/j.lwt.2015.01.034.

Donno, D., Mellano, M. G., Riondato, I., De Biaggi, M., Andriamaniraka, H., Gamba, G., \& Beccaro, G. L. (2019). Traditional and unconventional dried fruit snacks as a source of health-promoting compounds. Antioxidants, 8(396), 1-15. https://doi.org/10. 3390/antiox8090396.

Fava, F., Zanaroli, G., Vannini, L., Guerzoni, E., Bordoni, A., Viaggi, D., ... Brendle, H. G. (2013). New advances in the integrated management of food processing by-products in Europe: Sustainable exploitation of fruit and cereal processing by-products with the production of new food products (NAMASTE EU). New Biotechnology, 30(6), 647-655.

Fernandes, L., Casal, S., Pereira, J. A., Saraiva, J. A., \& Ramalhosa, E. (2017). Edible flowers: A review of the nutritional, antioxidant, antimicrobial properties and effects on human health. Journal of Food Composition and Analysis, 60, 38-50. https://doi. org/10.1016/j.jfca.2017.03.017.

Forbes, S. L., Kahiya, E., \& Balderstone, C. (2016). Analysis of Snack Food Purchasing and Consumption Behavior. Journal of Food Products Marketing, 22(1), 65-88.

Fruta desidratada Archives - Frubis. (n.d.). Retrieved June 13, 2020, from https:// frubisworld.com/fruta-desidratada/\#maca-vermelha.

Guimarães, R., Barros, L., Dueñas, M., Carvalho, A. M., Queiroz, M. J. R. P., SantosBuelga, C., \& Ferreira, I. C. F. R. (2013). Characterisation of phenolic compounds in wild fruits from Northeastern Portugal. Food Chemistry, 141(4), 3721-3730. https:// doi.org/10.1016/j.foodchem.2013.06.071.

Höglund, E., Eliasson, L., Oliveira, G., Almli, V. L., Sozer, N., \& Alminger, M. (2018). Effect of drying and extrusion processing on physical and nutritional characteristics of bilberry press cake extrudates. LWT, 92, 422-428. https://doi.org/10.1016/j.lwt. 2018.02.042.

Ieri, F., Martini, S., Innocenti, M., \& Mulinacci, N. (2013). Phenolic distribution in liquid preparations of vaccinium myrtillus L. and vaccinium vitis idaea L. Phytochemical Analysis, 24(5), 467-475.

Kuete, V., Kamga, J., Sandjo, L. P., Ngameni, B., Poumale, H. M., Ambassa, P., \& Ngadjui, B. T. (2011). Antimicrobial activities of the methanol extract, fractions and compounds from Ficus polita Vahl. (Moraceae). BMC Complementary and Alternative Medicine, 11(1), 6. https://doi.org/10.1186/1472-6882-11-6.

Li, J., Li, X. D., Zhang, Y., Zheng, Z. D., Qu, Z. Y., Liu, M., ... Qu, L. (2013). Identification and thermal stability of purple-fleshed sweet potato anthocyanins in aqueous solutions with various $\mathrm{pH}$ values and fruit juices. Food Chemistry, 136(3-4), 1429-1434.

Liu, H., Fan, Y., Wang, W., Liu, N., Zhang, H., Zhu, Z., \& Liu, A. (2012). Polysaccharides from Lycium barbarum leaves: Isolation, characterization and splenocyte proliferation activity. International Journal of Biological Macromolecules, 51(4), 417-422. https://doi.org/10.1016/j.ijbiomac.2012.05.025.

Łuczaj, Ł., Pieroni, A., Tardío, J., Pardo-De-Santayana, M., Sõukand, R., Svanberg, I., ... Kalle, R. (2012). Wild food plant use in 21st century Europe: The disappearance of old traditions and the search for new cuisines involving wild edibles. Acta Societatis Botanicorum Poloniae, 81(4), 359-370. https://doi.org/10.5586/asbp.2012.031.

Mikulic-Petkovsek, M., Schmitzer, V., Slatnar, A., Stampar, F., \& Veberic, R. (2015). A comparison of fruit quality parameters of wild bilberry (Vaccinium myrtillus L.) growing at different locations : Fruit quality parameters of wild bilberry. J. Sci. Food Agric. 95(4), 776-785. https://doi.org/10.1002/jsfa.2015.95.issue-410.1002/jsfa. 6897.

Mikulic-Petkovsek, M., Slatnar, A., Stampar, F., \& Veberic, R. (2012). HPLC-MS n identification and quantification of flavonol glycosides in 28 wild and cultivated berry species. Food Chemistry, 135(4), 2138-2146.

Može, Š., Polak, T., Gašperlin, L., Koron, D., Vanzo, A., Poklar Ulrih, N., \& Abram, V. (2011). Phenolics in slovenian bilberries (Vaccinium myrtillus L.) and blueberries (Vaccinium corymbosum L.). Journal of Agricultural and Food Chemistry, 59(13), 6998-7004.

Njike, V. Y., Smith, T. M., Shuval, O., Shuval, K., Edshteyn, I., Kalantari, V., \& Yaroch, A. L. (2016). Snack Food, Satiety, and Weight. Advances in Nutrition, 7(5), 866-878. 
https://doi.org/10.3945/an.115.009340.

Pires, T. C. S. P., Dias, M. I., Barros, L. \& Ferreira, I. C. F. R. (2017). Nutritional and chemical characterization of edible petals and corresponding infusions: Valorization as new food ingredients. Food Chemistry, 220, 337-343. https://doi.org/10.1016/j. foodchem.2016.10.026.

Pires, T. C. S. P., Barros, L., Santos-Buelga, C., \& Ferreira, I. C. F. R. (2019). Edible flowers: Emerging components in the diet. Trends in Food Science \& Technology, 93(October), 244-258. https://doi.org/10.1016/j.tifs.2019.09.020.

Pires, T. C. S. P., Caleja, C., Santos-Buelga, C., Barros, L., \& Ferreira, I. C. F. R. (2020) Vaccinium myrtillus L. Fruits as a Novel Source of Phenolic Compounds with Health Benefits and Industrial Applications - A Review. Current Pharmaceutical Design, 26, 1-12. https://doi.org/10.2174/1381612826666200317132507.

Pires, T. C. S. P., Dias, M. I., Barros, L., Alves, M. J., Oliveira, M. B. P. P., Santos-Buelga, C., \& Ferreira, I. C. F. R. (2018a). Antioxidant and antimicrobial properties of dried Portuguese apple variety (Malus domestica Borkh. cv Bravo de Esmolfe). Food Chemistry, 240(August 2017), 701-706. https://doi.org/10.1016/j.foodchem.2017. 08.010 .

Pires, T. C. S. P., Dias, M. I., Barros, L., Barreira, J. C. M., Santos-Buelga, C., \& Ferreira, I. C. F. R. (2018d). Incorporation of natural colorants obtained from edible flowers in yogurts. LWT, 97, 668-675.

Pires, T. C. S. P., Dias, M. I., Barros, L., Calhelha, R. C., Alves, M. J., Oliveira, M. B. P. P., ...
Ferreira, I. C. F. R. (2018c). Edible flowers as sources of phenolic compounds with bioactive potential. Food Research International, 105(2017), 580-588. https://doi. org/10.1016/j.foodres.2017.11.014

Pires, T. C. S. P., Dias, M. I., Barros, L., Calhelha, R. C., Alves, M. J., Santos-Buelga, C., \& Ferreira, I. C. F. R. (2018b). Phenolic compounds profile, nutritional compounds and bioactive properties of Lycium barbarum L.: A comparative study with stems and fruits. Industrial Crops and Products, 122, 574-581. https://doi.org/10.1016/j. indcrop.2018.06.046.

Sepúlveda, M., Quitral, V., Schwartz, M., Vio, F., Zacarias, I., \& Werther, K. (2011) Health properties and sensory quality of apple snack destined for school feeding. Archivos Latinoamericanos de Nutricion, 61(4), 423-428.

Verain, M. C. D., Dagevos, H., \& Antonides, G. (2015). Sustainable food consumption. Product choice or curtailment? Appetite, 91, 375-384. https://doi.org/10.1016/J. APPET.2015.04.055.

Vrhovsek, U., Masuero, D., Palmieri, L., \& Mattivi, F. (2012). Identification and quantification of flavonol glycosides in cultivated blueberry cultivars. Journal of Food Composition and Analysis, (1), 9-16. https://doi.org/10.1016/j.jfca.2011.04.015.

Zorenc, Z., Veberic, R., Stampar, F., Koron, D., \& Mikulic-Petkovsek, M. (2016). White versus blue: Does the wild "albino" bilberry (Vaccinium myrtillus L.) differ in fruit quality compared to the blue one? Food Chemistry, 211, 876-882. https://doi.org/10. 1016/j.foodchem.2016.05.142. 